\title{
Experimental Results of the Superluminescent Fiber Laser Sources for Fiber Optic Sensors
}

\author{
E. F. Pinzón-Escobar ${ }^{* 1}$, G. E. Sandoval-Romero ${ }^{2}$ \\ ${ }^{1,2}$ Centro de Ciencias Aplicadas y Desarrollo Tecnológico, \\ Universidad Nacional Autónoma de México, \\ Circuito Exterior S/N, Ciudad Universitaria, \\ A. P. 70-186, Delegación Coyoacán, C.P. 04510, México D. F. Mexico. \\ *enrique.pinzon@ccadet.unam.mx
}

\author{
1ST INTERNATIONAL \\ CONGRESS ON \\ INSTRUMENTATION AND \\ APPLIED SCIENCES
}

\begin{abstract}
We are presenting experimental work on an erbium-doped fiber operating in the superluminescent regime. Experimental results for different pump power levels and fiber length show that the theoretical and numerical model could render useful information for predicting the total output power as a function of fiber doped length and the input pump power. These types of sources could have direct application in wavelength multiplexed arrangements of fiber sensors, fiber gyroscopes or, in general, in any sensors in which a broad wavelength and stable light source is required.
\end{abstract}

Keywords: Doped fiber optic, erbium, sensors of physical magnitudes, fiber optic.

\section{RESUMEN}

Este es un trabajo experimental de una fibra óptica dopada con erbio trabajando en régimen superluminiscente. Los resultados experimentales para diferentes niveles de bombeo óptico y longitud de la fibra, muestran que el modelo teórico y numérico pueden ser usados para predecir la potencia total de salida como función de la longitud de la fibra dopada y la potencia de bombeo. Este tipo de fuentes podría tener directa aplicación en arreglos multiplexados por longitud de onda de sensores en fibra óptica, giroscopios en fibra óptica o en general, en cualquier sensor en donde ser requiera un amplio ancho espectral y una fuente de luz estable.

\section{Introduction}

Superluminescent rare-earth-doped fiber sources (SFS) output is simply amplified spontaneous emission (ASE) generated by the inverted ions of the doped fiber, which are confined by the core in both the forward direction and backward direction, the emitted photons are amplified as they travel along the fiber. Due to this, ASE does not have a resonator; the spectral emission covers a broad fraction of the bandwidth of the laser transition, typically a few tens of nanometers. A superluminescent rare-earth-doped fiber source is capable of providing high output power and exhibiting excellent thermal stability; because of these characteristics, it is interesting for several sensor applications, particularly for fiber gyroscopes. This paper focuses on predicting the ASE output power for erbium fiber as a function of fiber doped length and input pump power at 980 $\mathrm{nm}$ wavelength.

\section{Theory}

We used a modified version of the rate equation for a three-state laser source with some considerations for a superluminescent light source [1], that described the evolution of the signal and pumped power along the fiber, considering an unidirectional pump, doped fiber, with the pump launched at $z=0$ and propagating in the $+z$ direction, parallel to the doped fiber axis. We used the following equations [2]:

$\frac{d P_{p}(z)}{d z}=-\gamma_{p}(z) P_{p}(z)$

From Equations (1) and (2), $P_{p}(z)$ is the pump power; $\gamma_{p}(z)$ is the absorption coefficient, $P_{s}^{ \pm}\left(z, \lambda_{i}\right)$ is the output power, which is dependent on the light wavelength and on the position along the optical fiber; $P_{s}^{+}\left(z, \lambda_{i}\right)$ represents the signal 


$$
\begin{aligned}
\frac{d P_{s}^{ \pm}\left(z, \lambda_{i}\right)}{d z}= & \pm\left\{G_{e}\left(z, \lambda_{i}\right)\left[P_{s}^{ \pm}\left(z, \lambda_{i}\right)+P_{0}\right]\right. \\
& \left.-G_{a}\left(z, \lambda_{i}\right) P_{s}^{ \pm}\left(z, \lambda_{i}\right)\right\}
\end{aligned}
$$

propagating in the direction of the pump beam and $P_{s}^{-}\left(z, \lambda_{i}\right)$ represents the signal that propagates in the opposite direction; $G_{e}\left(z, \lambda_{i}\right)$ is the amplification coefficient of spontaneous emission and $G_{a}\left(z, \lambda_{i}\right)$ is the absorption coefficient of spontaneous emission respectively; $P_{0}$ is the input spectrum density equivalent of the spontaneous emission radiation, defined by two polarization states [3]:

$$
P_{0}=2 h v_{s} \Delta v
$$

$v_{s}$ is the frequency of the signal, and $\Delta v=\left(c / \lambda_{s}^{2}\right) \Delta \lambda_{s}$.

For simplicity, from Equation (1) we can consider $\gamma_{p}(z)$ constant when $P_{p}(z)>P_{p}^{\text {th }}$, where $P_{p}^{\text {th }}$ is the threshold power, and depending on the parameters of fiber optics doped, it is described as follows:

$P_{p}^{t h}=\pi \mathrm{a}^{2} \frac{h v_{p}}{\sigma_{p} \tau}$

Then Equation (1) acquires the form [3]:

$$
\frac{d P_{p}(z)}{d z}=-N_{T} \pi a^{2} \frac{h v_{p}}{\tau}
$$

Where $\sigma_{p}$ is the transition cross section absorption of pumping which is assumed as $2.5 \times 10^{-25} \mathrm{~m}^{2}$ from the literature [1]; $\tau=12 \times 10^{-3} \mathrm{~s}$ is the lifetime of the upper working level for spontaneous radiation [1]; $a=2 \times 10^{-6} \mathrm{~m}$ is the radius of the core optical fiber; $v_{p}=3.071 \times 10^{14} \mathrm{~Hz}$ is the frequency of pumping; $h$ is Planck's constant; $N_{T}=1.9 \times 10^{25}$ ions $/ \mathrm{m}^{3}$ is the concentration of ions of Erbium.

We used the differential Equation (5) to simplify the calculation and because we assumed small ASE signal regime, then solving Equation (5) with boundary conditions $P_{p}(0)=P_{i n}$, where $P_{i n}$ is the initial pump power at the input end of the active fiber, and is written as:

$$
P_{p}(z)=P_{i n}-\left(N_{T} \pi a^{2} \frac{h v_{p}}{\tau}\right) z
$$

From the last assumption and focusing on Equation (6), we can define the coefficients $G_{e}\left(z, \lambda_{i}\right)$ and $G_{a}\left(z, \lambda_{i}\right)$ as following form [3]:

$G_{e}\left(z, \lambda_{i}\right)=N_{T} \sigma_{e}\left(\lambda_{i}\right)(1-\eta)\left[\frac{\frac{P_{p}(z)}{P_{p}^{t h}}}{\frac{P_{p}(z)}{P_{p}^{t h}}+1}\right]$

$G_{a}\left(z, \lambda_{i}\right)=N_{T} \sigma_{a}\left(\lambda_{i}\right)(1-\eta)\left[\frac{1}{\frac{P_{p}(z)}{P_{p}^{t h}}+1}\right]$

$\eta=\exp \left(\frac{a^{2}}{\omega_{s}^{2}}\right)$

Results obtained from Equation (6) are presented in Figure 1. These results were obtained for different values of $P_{i n}$, as a function of the fiber length.

Similarly, for Equation (2) we obtain two solutions:

$$
\begin{aligned}
& P_{s}^{+}\left(z, \lambda_{i}\right)=\left(\frac{G_{e}\left(z, \lambda_{i}\right)}{G_{b}\left(z, \lambda_{i}\right)} P_{0} e^{z G_{b}\left(z, \lambda_{i}\right)}-\frac{G_{e}\left(z, \lambda_{i}\right)}{G_{b}\left(z, \lambda_{i}\right)}\right) \\
& P_{s}^{-}\left(z, \lambda_{i}\right)=\left(\frac{G_{e}\left(z, \lambda_{i}\right)}{G_{b}\left(z, \lambda_{i}\right)} P_{0} e^{(L-z) G_{b}\left(z, \lambda_{i}\right)}-\frac{G_{e}\left(z, \lambda_{i}\right)}{G_{b}\left(z, \lambda_{i}\right)}\right)
\end{aligned}
$$

Where $L$ is the length of the erbium doped fiber optic and $G_{b}\left(z, \lambda_{i}\right)$ is known as net gain coefficient: 


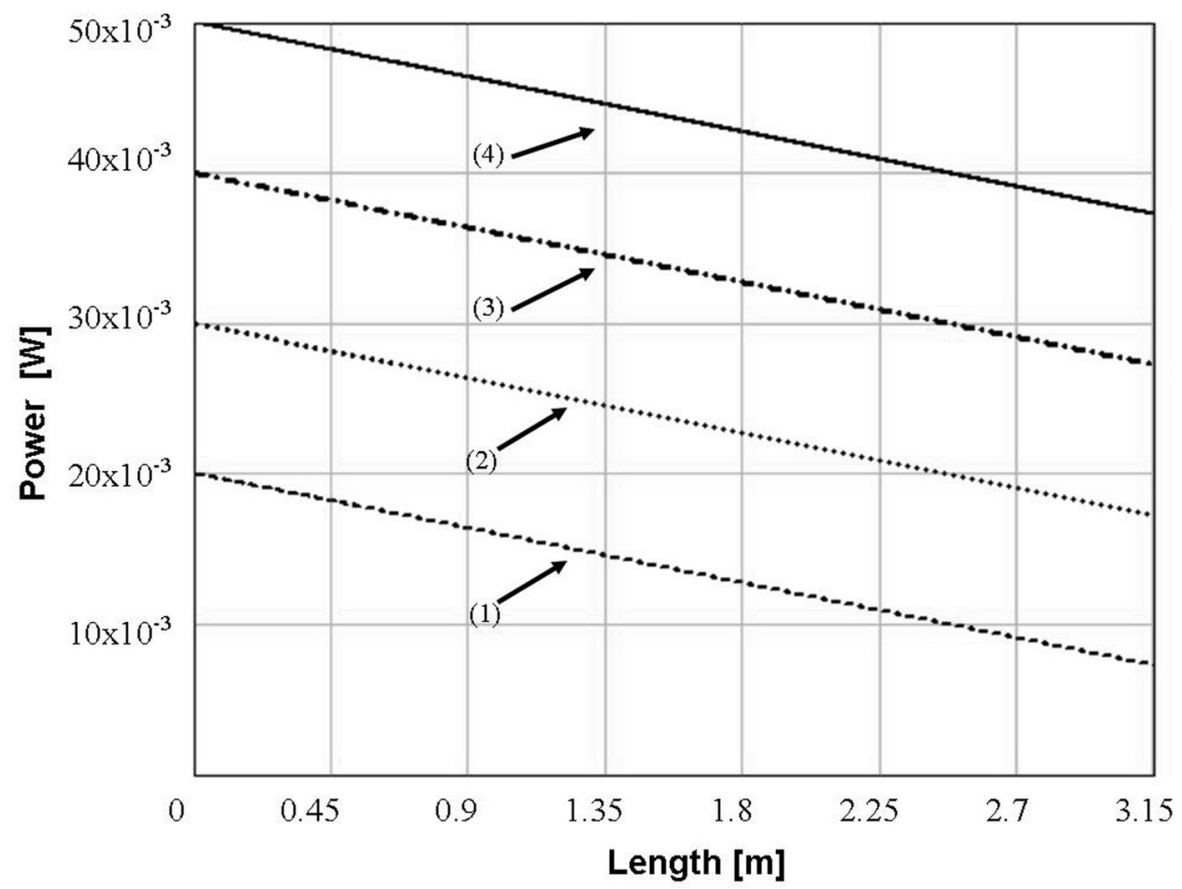

Figure 1. Different input pump power as a function of the fiber length, (1) $P_{i n}=20 \times 10^{-3}[\mathrm{~W}]$, (2) $P_{i n}=30 \times 10^{-3}[\mathrm{~W}]$, (3) $P_{i n}=40 \times 10^{-3}[\mathrm{~W}]$, (4) $P_{i n}=50 \times 10^{-3}[\mathrm{~W}]$.

$$
G_{b}\left(z, \lambda_{i}\right)=G_{e}\left(z, \lambda_{i}\right)-G_{a}\left(z, \lambda_{i}\right)
$$

Figure 2 and 3 show the output ASE signals at $1550 \mathrm{~nm}$ (peak superluminiscent wavelength) for the pump powers $P_{p}(z)$ shown in Figure 1. Figure 2 corresponds to the signal propagation in the forward direction $\left(P_{s}^{+}\left(z, \lambda_{i}\right)\right)$ of the pump power at $980 \mathrm{~nm}$ and Figure 3 shows the signal in the backward direction $\left(P_{s}^{-}\left(z, \lambda_{i}\right)\right)$ of the pump power.

Equations (10) and (11) with wavelength dependent coefficients $G_{a}\left(z, \lambda_{i}\right)$ and $G_{e}\left(z, \lambda_{i}\right)$ [3, 4] which describe in general the absorption and emission, where for a given fiber-doped length and input pump power condition $P_{p}(0)=P_{i n}$ the total gain varies along the doped fiber where for some portions the emission is bigger than the absorption and for other portions the absorption is bigger than the emission. This property can be observed simulating the net gain from Equation (12), as shown in Figure 4.

\section{Measurements, experimental setup and results}

The superluminiscent source was implemented with the double-pass configuration shown in Figure 5 (other configurations can be found in [5]), however we did not use the reflector on the backward output owing to the fact that we wanted to measure both outputs. This configuration uses a wavelength division multiplexing (WDM) fiber coupler to filter out the pump from the output ASE signal. The WDM operates at $980 \mathrm{~nm}$ and 1550 $\mathrm{nm}$ wavelengths.

The pump signal was made by a pigtailed laser diode at $980 \mathrm{~nm}$ wavelength that it was controlling the output power (by the supply current) and the operating temperature, this characteristic helps to guarantee thermal stability for the superluminescent fiber source. Also in this work we used $3.15 \mathrm{~m}$ of single mode erbium fiber doped with a radius core of $2 \times 10^{-6} \mathrm{~m}$ and $1.9 \times 10^{25}$ ions $/ \mathrm{m}^{3}$ concentration of erbium-doped fiber. 


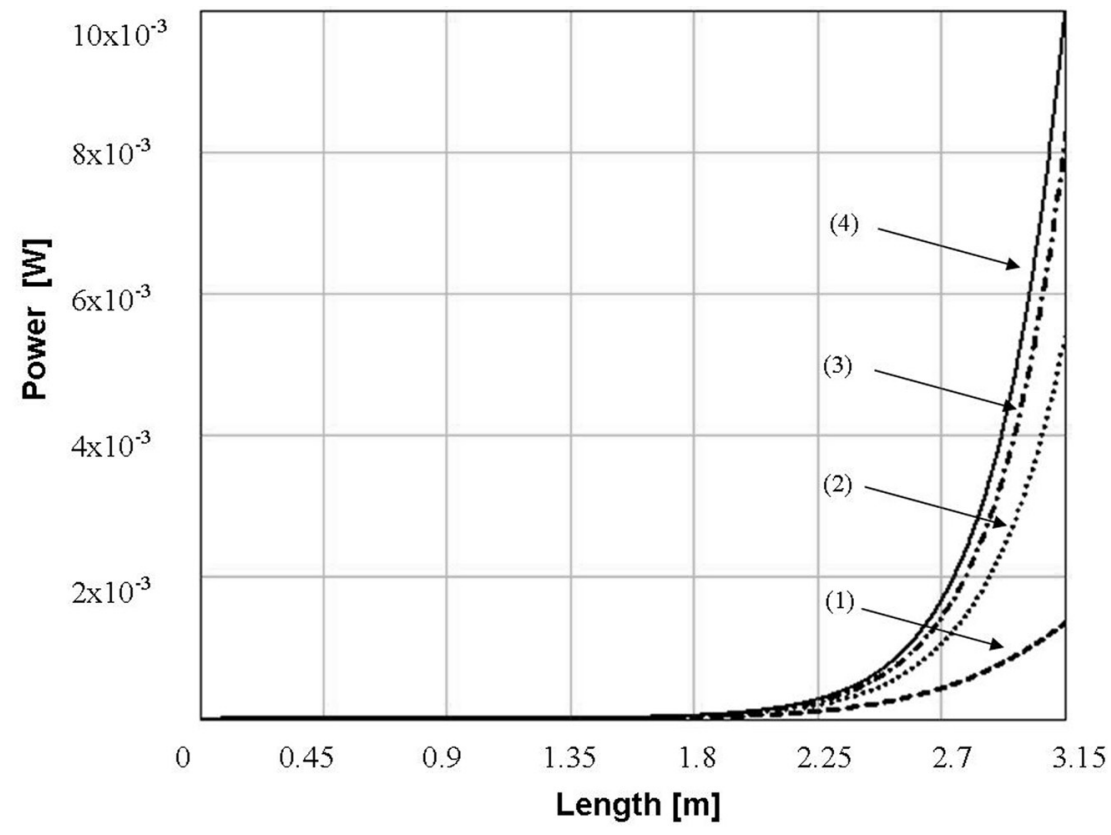

Figure 2. Theoretical amplified spontaneous emission $\left(P_{s}^{+}\left(z, \lambda_{i}\right)\right)$ in the forward direction as a function of the fiber length, for different input pump power

(1) $P_{i n}=20 \times 10^{-3}[\mathrm{~W}]$, (2) $P_{i n}=30 \times 10^{-3}[\mathrm{~W}]$, (3) $P_{i n}=40 \times 10^{-3}[\mathrm{~W}]$, (4) $P_{i n}=50 \times 10^{-3}[\mathrm{~W}]$.

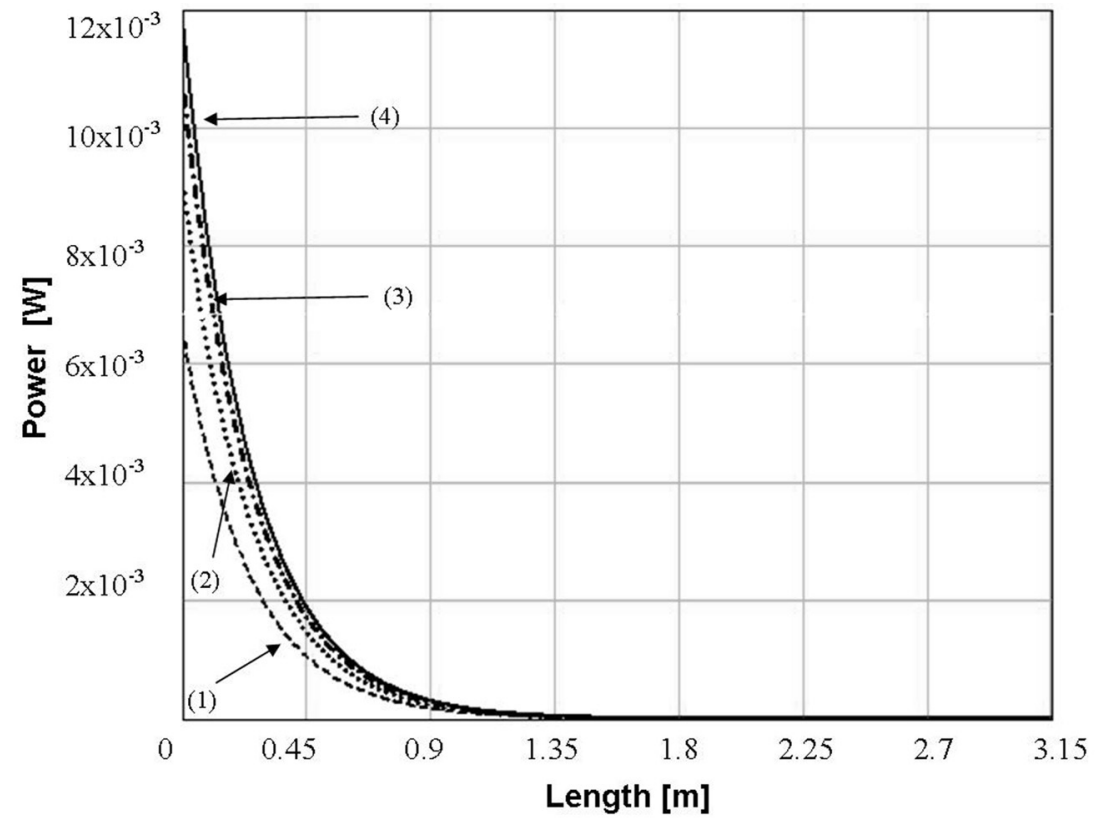

Figure 3. Theoretical amplified spontaneous emission $\left(P_{s}^{-}\left(z, \lambda_{i}\right)\right)$ in the backward direction as a function of fiber length, for different input pump power

(1) $P_{i n}=20 \times 10^{-3}[\mathrm{~W}],(2) P_{i n}=30 \times 10^{3}[\mathrm{~W}]$, (3) $P_{i n}=40 \times 10^{-3}[\mathrm{~W}]$, (4) $P_{i n}=50 \times 10^{-3}[\mathrm{~W}]$. 


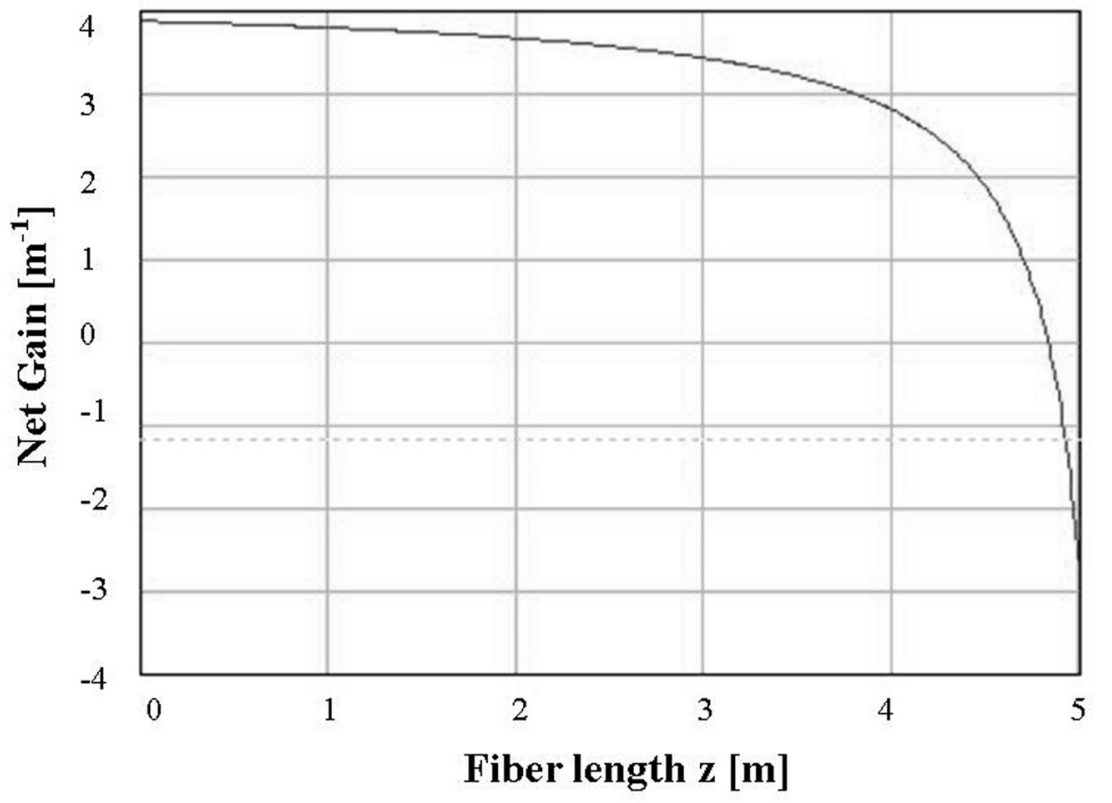

Figure 4. Net gain coefficient as function of fiber length $z$, for ASE wavelength signal at $1550 \mathrm{~nm}$ and initial input power $P_{\text {in }}=20 \times 10^{-3}[\mathrm{~W}]$.

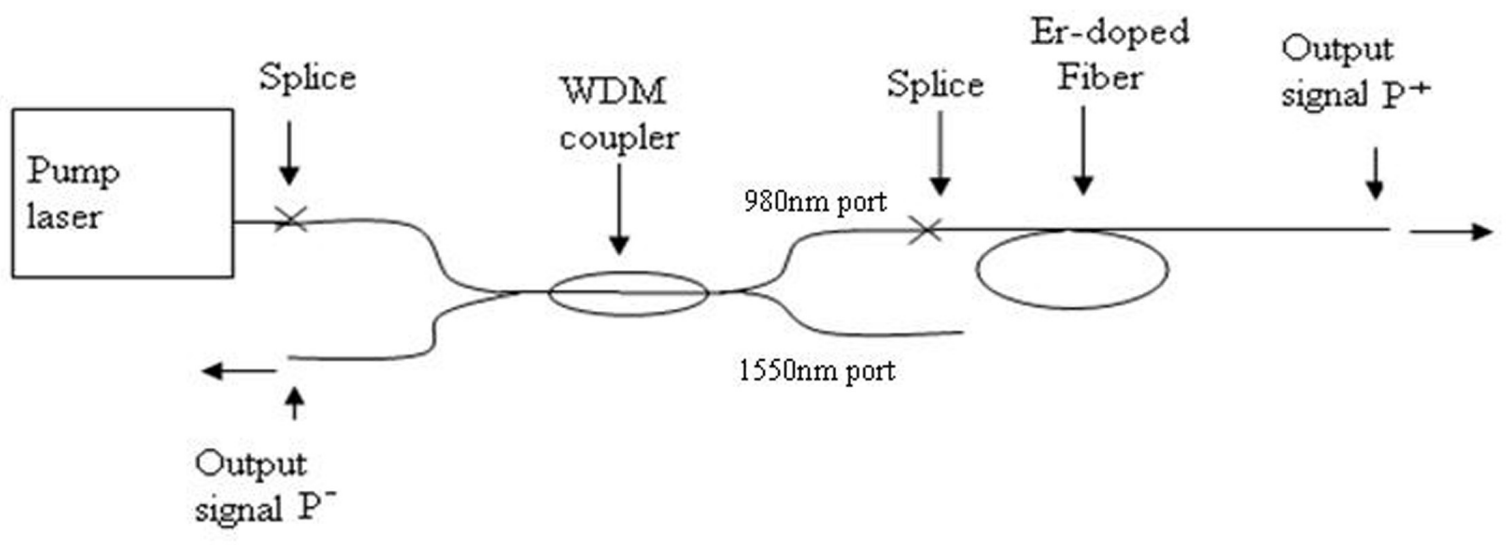

Figure 5. Experimental setup superluminiscent fiber laser source. 
In this work, the superluminiscent output signal is measured in forward and backward directions of propagation. In both cases, the output power depends on the pump power and on the length of the erbium-doped fiber optics $L=3.15 \mathrm{~m}$. The results of the input pump power are shown in Figure 6.

Amplified spontaneous emission (ASE) powers were measured experimentally using the pump power shown in Figure 6, in the forward direction $P^{+}$and the backward direction $P^{-}$, these ASE powers are shown in Figures 7 and 8, respectively.

If we compare the output power in Figure 7 and 8 with the theoretical part, they have opposite behavior (the output power in $P^{+}$is higher than the output power in $P^{-}$), hence the forward output power is greater than the predicted in the theoretical part and the backward output power is lower than the theoretical calculus; nevertheless, the output power is close to the expected value, this means that there is a reflection from the backward output to forward direction.

In Figure 9, we can see two signals, a $976.8 \mathrm{~nm}$ wavelength emission that corresponds to the diode laser, and the other one with wavelength peak at $1556.8 \mathrm{~nm}$, this signal is the amplified spontaneous emission produced by our superluminiscent source with a $40 \mathrm{~nm}$ spectral bandwidth.

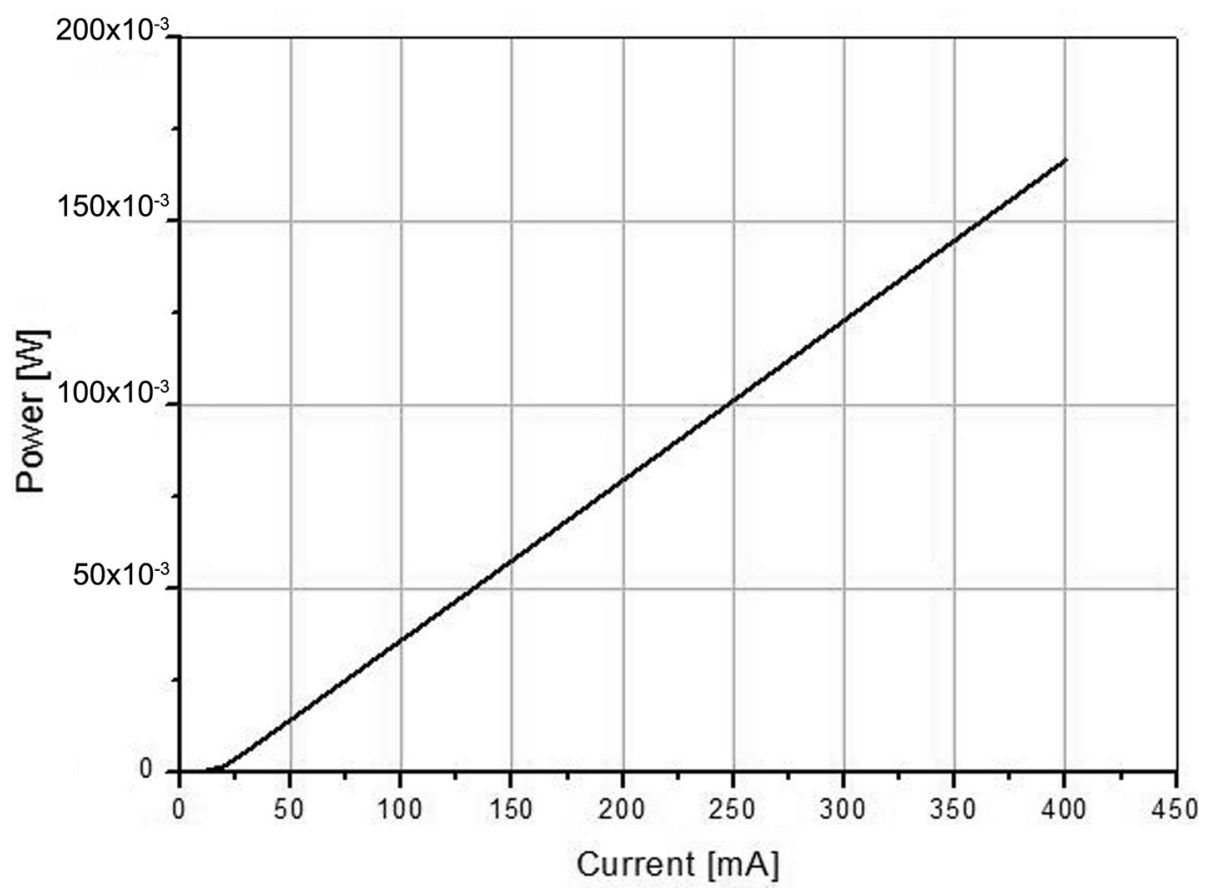

Figure 6. Experimental input pump power at $976.8 \mathrm{~nm}$ of wavelength. 


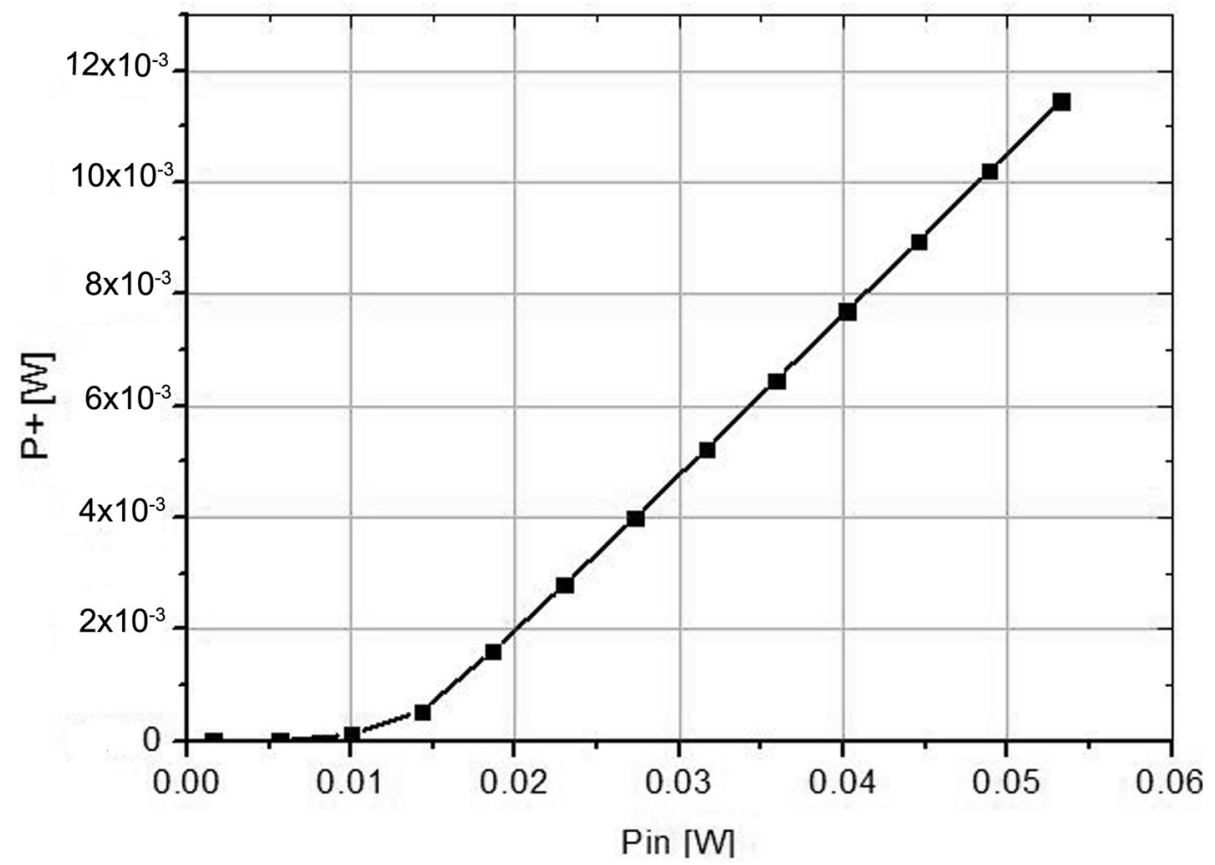

Figure 7. Output ASE power $P^{+}$at $1550 \mathrm{~nm}$ wavelength.

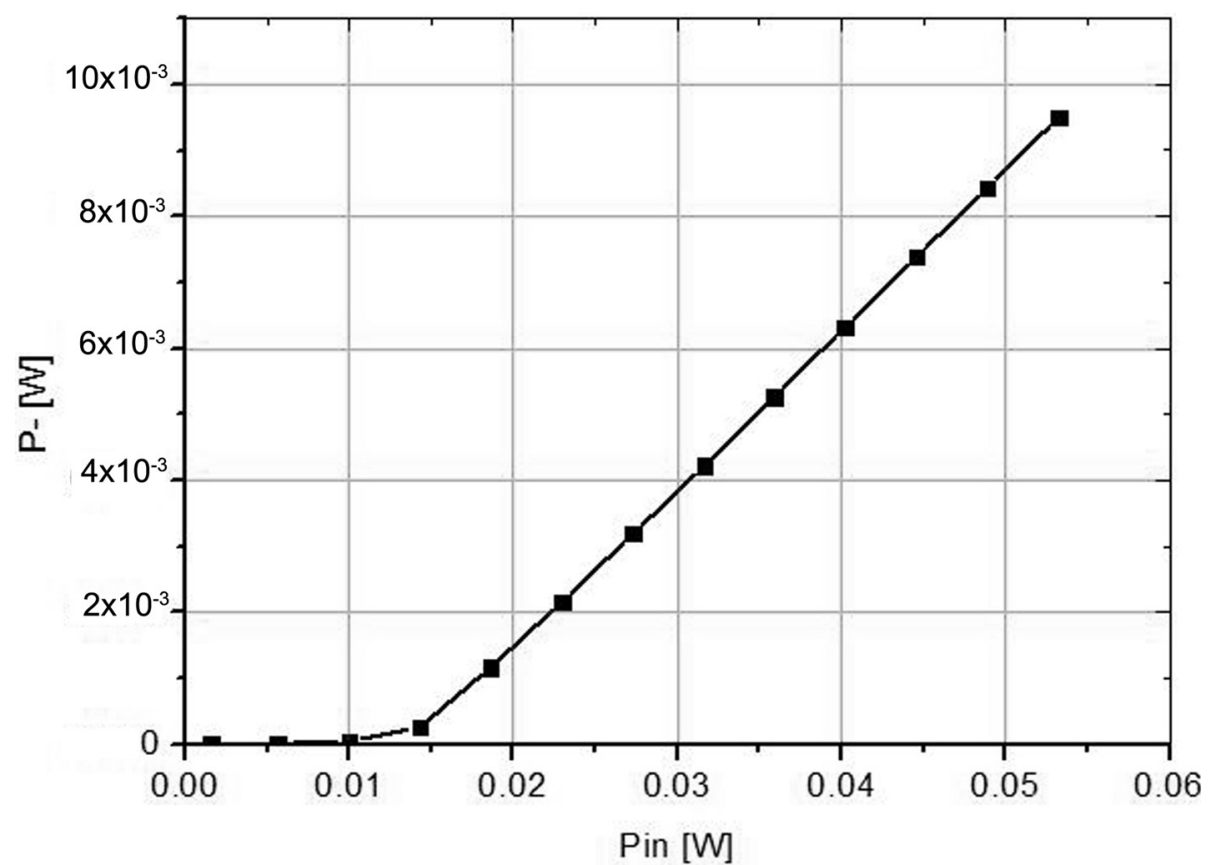

Figure 8. Output ASE power $P^{-}$at $1550 \mathrm{~nm}$ wavelength. 


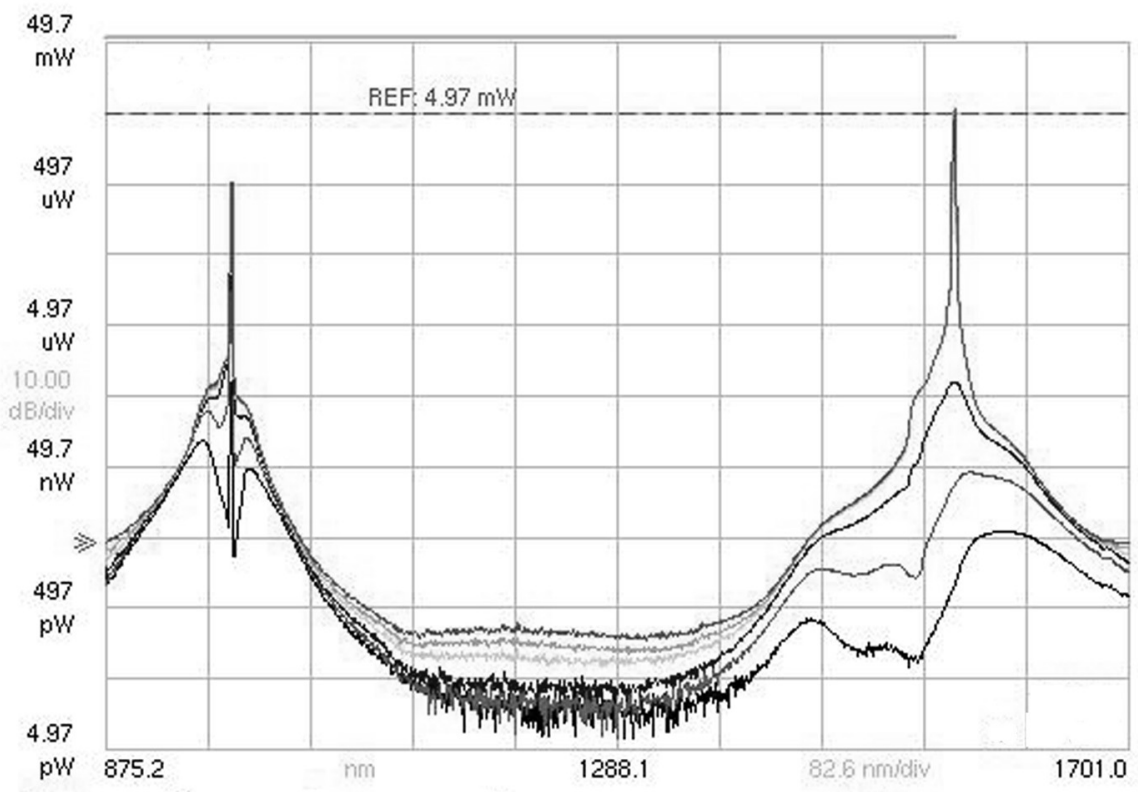

Figure 9. Output ASE and laser spectra measured at the end of the erbium doped fiber with the fiber length $L=3.15 \mathrm{~m}$.

\section{Conclusions}

We have theoretical and experimental results which show that we can calculate the pumping power to create a superluminiscent erbium-doped fiber source with an optimum length as a function of maximum power output, where the backward ASE signal is the most efficient for three-level systems; we also support the proposal about using superluminiscent fiber laser sources in lowcoherence sensors because these kind of light sources have excellent thermal stability, spectral broadband and high output power.

\section{References}

[1] R. F. Kalman. M. J. F. Digonnet. \& P. F. Wysocki., Modeling of three level laser superfluorescent fiber sources, Fiber Laser Sources and Amplifiers II, Proc. SPIE 1373, 1990, pp. 209-222, San Jose, California, USA., September.
[2] G. E. Sandoval-Romero. V. Argueta-Díaz. \& O. Pottiez., Theoretical results of the analytical and numerical solutions of superluminescent fiber sources, Physica Status Solidi C 6, No. S1, May, 2009, pp. S227S230.

[3] G. E. Sandoval-Romero. \& V. A. Nikolaev., Límite de detección de un giroscopio de fibra óptica usando una fuente de radiación superluminiscente, Revista Mexicana de Física, Vol. 49, No. 2, Abril, 2003, pp. 155-165.

[4] M. J. F. Digonnet., Selected Papers on Rare-EarthDoped Fiber Lasers Sources and Amplifiers, SPIE Optical Engineering Press, Vol. MS 37, 1992, pp. 694.

[5] M. J. F. Digonnet., Rare-Earth- Doped Fiber Lasers and Amplifiers, 2d Ed., Marcel Dekker Inc., 2001, pp. 777.

\section{Acknowledgments}

This work was supported by CONACyT grant No. J50494-Y, Mexico. 